Supporting information for Langmuir

\title{
Rapid Micelle-Mediated Size-Controlled Fabrication of Calcium Sulfate Nanorods Using Silver Nanoparticles
}

Taichi Nakagawa, ${ }^{1}$ Willie L. Hinze, ${ }^{\ddagger}$ Yoshitaka Takagai*t

${ }^{t}$ Faculty of Symbiotic Systems Science, Cluster of Science and Technology, Fukushima University, 1 Kanayagawa, Fukushima 960-1296, JAPAN,

${ }^{\ddagger}$ Department of Chemistry, Wake Forest University, P. O. Box 7486, Winston-Salem, North Carolina 27109 U.S.A

Number of pages: 8

Number of figures: 5

Number of schemes: 0

Number of tables: 0

\section{Table of Contents}

Section

$\underline{\text { Page }}$

1. Preparation and synthesis of nanoparticles (NPs) $\quad \mathrm{S} 2$

2. Characterization of Ag-NPs prepared by $\mathrm{NaBH}_{4}$ method $\quad \mathrm{S} 3$

3. Characterization of Ag-NPs prepared by citrate reduction method $\quad \mathrm{S} 4$

4. Characterization of Au-NPs prepared by trisodium citrate S5

5. The solubility of CS at different temperatures S6

6. The impact of temperature on the volume of and $\begin{array}{ll}\text { percent water in the Triton X-114 surfactant-rich phase } & \text { S7 }\end{array}$

7. References $\quad$ S8

*To whom correspondence should be addressed: s015@ipc.fukushima-u.ac.jp 


\section{Preparation and synthesis of nanoparticles (NPs)}

Chemicals

For preparation and synthesis of nanoparticles (NPs), sodium borohydride powder $\left(\mathrm{NaBH}_{4} \geq 98.0 \%\right)$, gold (III) chloride trihydrate $\left(\mathrm{HAuCl}_{4} \cdot 3 \mathrm{H}_{2} \mathrm{O} \geq 99.9 \%\right)$, silver nitrate $\left(\mathrm{AgNO}_{3} \geq 99.8 \%\right)$ and trisodium citrate dihydrate $\left(\mathrm{Na}_{3} \mathrm{C}_{6} \mathrm{H}_{5} \mathrm{O}_{7} \cdot 2 \mathrm{H}_{2} \mathrm{O} \geq 99.0 \%\right)$ were used. The ethylene glycol coated Ag-NPs was obtained from Aldrich.

\section{Apparatus}

Following synthesis, the NPs were characterized using V-650 spectrophotometer (JASCO Corporation, Japan) and a SZ-100 dynamic light scattering photometer (DLS, HORIBA, Ltd., Japan). Light source: $532 \mathrm{~nm} 10 \mathrm{~mW}$ semiconductor excitation solid-state laser. The particle size measurement angle is $90^{\circ}$. Triplicate measurements were made at constant temperature $\left(25^{\circ} \mathrm{C}\right)$. A quartz cuvette $(10 \times 10 \times 45 \mathrm{~mm})$ fluorometer grade (GL Sciences Inc., Japan) was used for the spectral measurements. A JEM-1400 (JEOL, Ltd., Japan) transmission electron microscope (TEM) was used under an acceleration voltage of $120 \mathrm{kV}$ with magnification from 30,000 to 50,000.

\section{Procedure}

Preparation of Ag-NPs (26 nm diameter) by $\mathrm{NaBH}_{4}$ method using modified literature procedure. $^{1}$

$20 \mathrm{~mL}$ of $2.0 \mathrm{mM}$ sodium borohydride aq. sol. was added to a beaker $(50 \mathrm{~mL})$, and the mixture was stirred in ice bath $\left(4^{\circ} \mathrm{C}\right)$ for $20 \mathrm{~min}$. Then, $6.5 \mathrm{~mL}$ of $2.0 \mathrm{mM}$ silver nitrate aq. sol. was slowly added dropwise $(6 \mu \mathrm{L} / \mathrm{s})$ into the cool beaker (ice bath). After stirring for $60 \mathrm{~min}$, the beaker was removed from the ice bath. The solution was stored in room temperature. The solution was characterized using UV-vis spectrometer, DLS and TEM. The results are shown in Figure S1 (a) to (c). DLS results indicated that the prepared Ag-NPs had an average diameter $26.1 \pm 9.9 \mathrm{~nm}$ (mode diameter $22.8 \mathrm{~nm}$ ).

Note: In the presence of a large excess of $\mathrm{NaBH}_{4}$ (2-fold or greater relative to the $\mathrm{Ag}$ ion concentration), the AgNPs were reported to be stable at room temperature for several weeks. ${ }^{1}$ In this work, such prepared AgNPs were stable for at least 3 days. However, these $\mathrm{NaBH}_{4}$ prepared AgNPs were always used as soon as possible after their preparation in this study. 
(b)
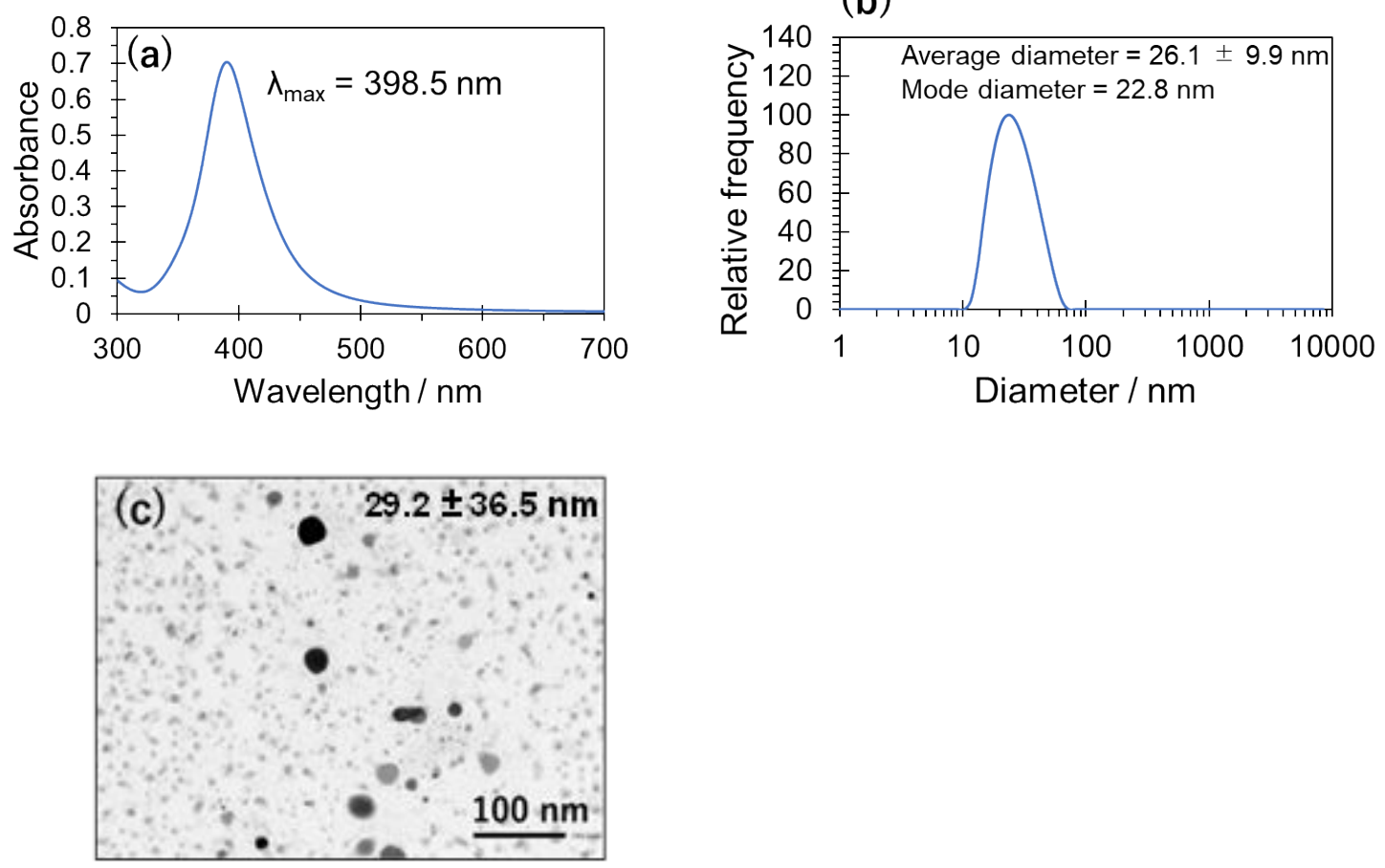

Figure S1. Characterization of Ag-NPs prepared by $\mathrm{NaBH}_{4}$ method: (a) absorption spectrum, (b) DLS profile and (c) TEM photograph. 
Preparation of Ag-NPs (81 nm diameter) by citrate reduction method using modified literature procedure. ${ }^{2}$

$10.0 \mathrm{~mL}$ of $1.0 \mathrm{mM}$ silver nitrate aq. sol. was added into a $30.0 \mathrm{~mL}$ beaker and the solution brought to a boil after which $0.4 \mathrm{~mL}$ of $1.0 \mathrm{w} / \mathrm{w} \%$ trisodium citrate dihydrate aq. sol. was added with stirring. Boiling with stirring was continued for another 15 min after which the mixture was cooled to and stored at room temperature. The solution was identified by UV-vis spectrometer, DLS and TEM. The results are shown in Figure S2 (a) to (c). The solution was characterized using UV-vis spectrometer, DLS and TEM. The results are shown in Figure S2 (a) to (c). DLS results indicated that the prepared Ag-NPs had an average diameter $81.1 \pm 74.7 \mathrm{~nm}$ (mode diameter $47.5 \mathrm{~nm}$ ).

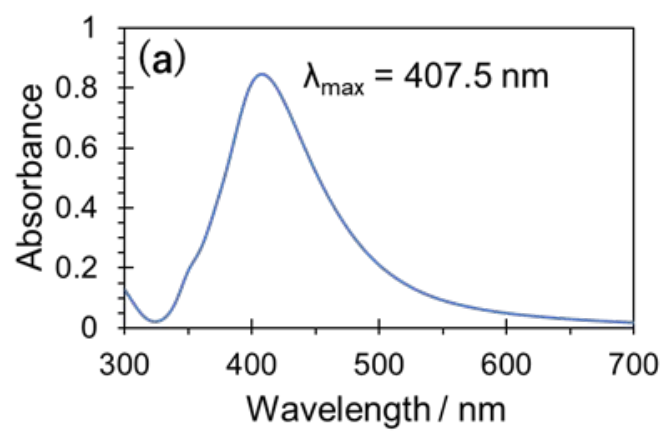

(b)
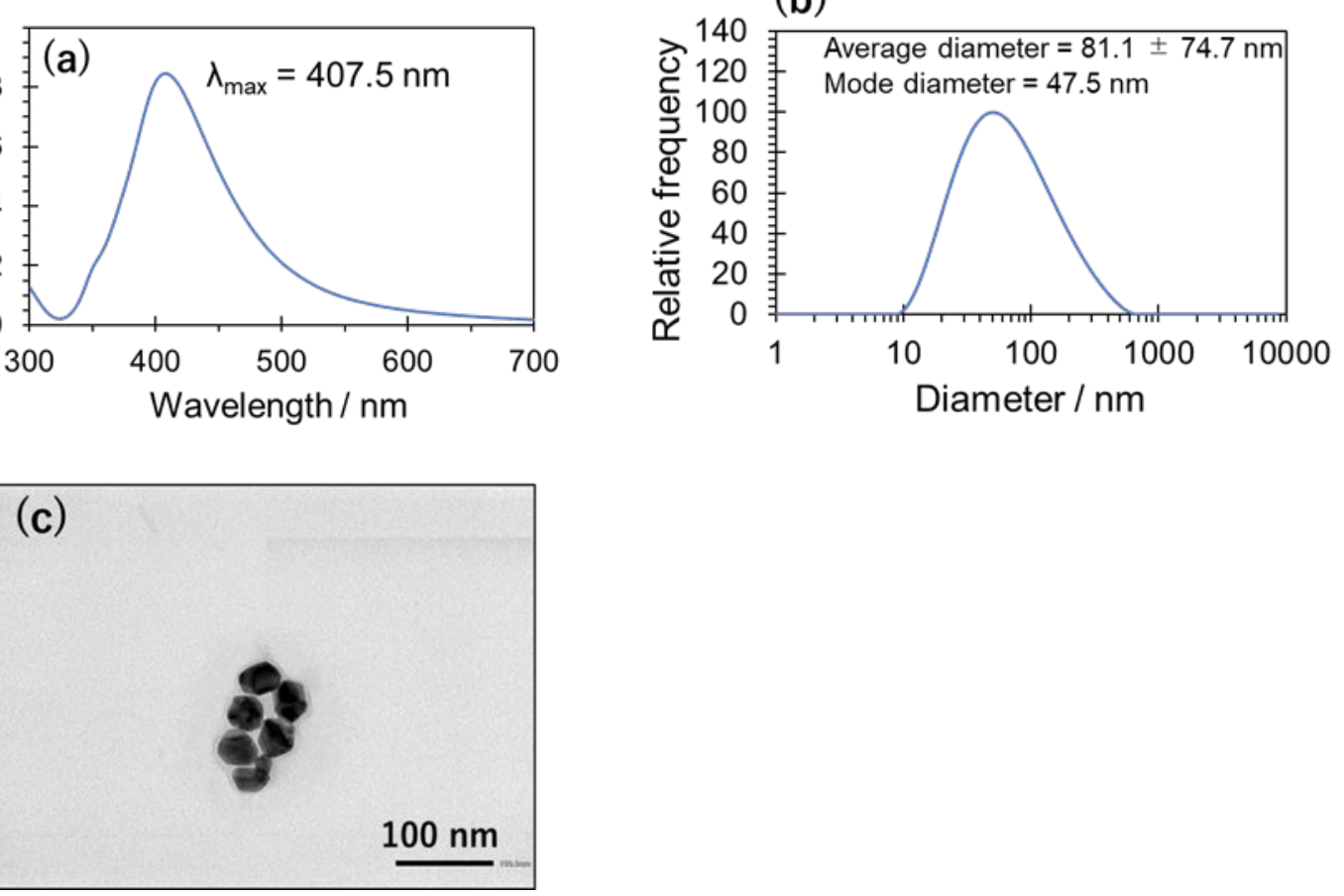

Figure S2. Characterization of Ag-NPs prepared by citrate reduction method: (a) absorption spectrum, (b) DLS profile and (c) TEM photograph. 
Preparation of Au-NPs (67 $\mathrm{nm}$ diameter) by citrate reduction method using modified literature procedure. ${ }^{3}$

$3.0 \mathrm{~mL}$ of $3.0 \mathrm{mM}$ trisodium citrate dihydrate aq. sol was added to a $10.0 \mathrm{~mL}$ centrifuge tube and the mixture heated for $7 \mathrm{~min}$ in oil bath $\left(108^{\circ} \mathrm{C}\right)$. Next, $3.0 \mathrm{~mL}$ of $1.0 \mathrm{mM}$ gold(III) chloride trihydrate $\left(\mathrm{HAuCl}_{4} \cdot 3 \mathrm{H}_{2} \mathrm{O}\right)$ aq solution was added, and the mixture was further heated for another $7 \mathrm{~min}$ in an oil bath $\left(108^{\circ} \mathrm{C}\right)$. After that, the solution was cooled to room temperature and stored at a temperature under $5^{\circ} \mathrm{C}$. The solution was identified by UV-vis spectrometer, DLS and TEM. The results are shown in Figure S3 (a) to (c). The solution was characterized using UV-vis spectrometer, DLS and TEM. The results are shown in Figure S3 (a) to (c). DLS results indicated that the prepared Au-NPs had an average diameter $66.9 \pm 66.5 \mathrm{~nm}$ (mode diameter $37.2 \mathrm{~nm}$ ).
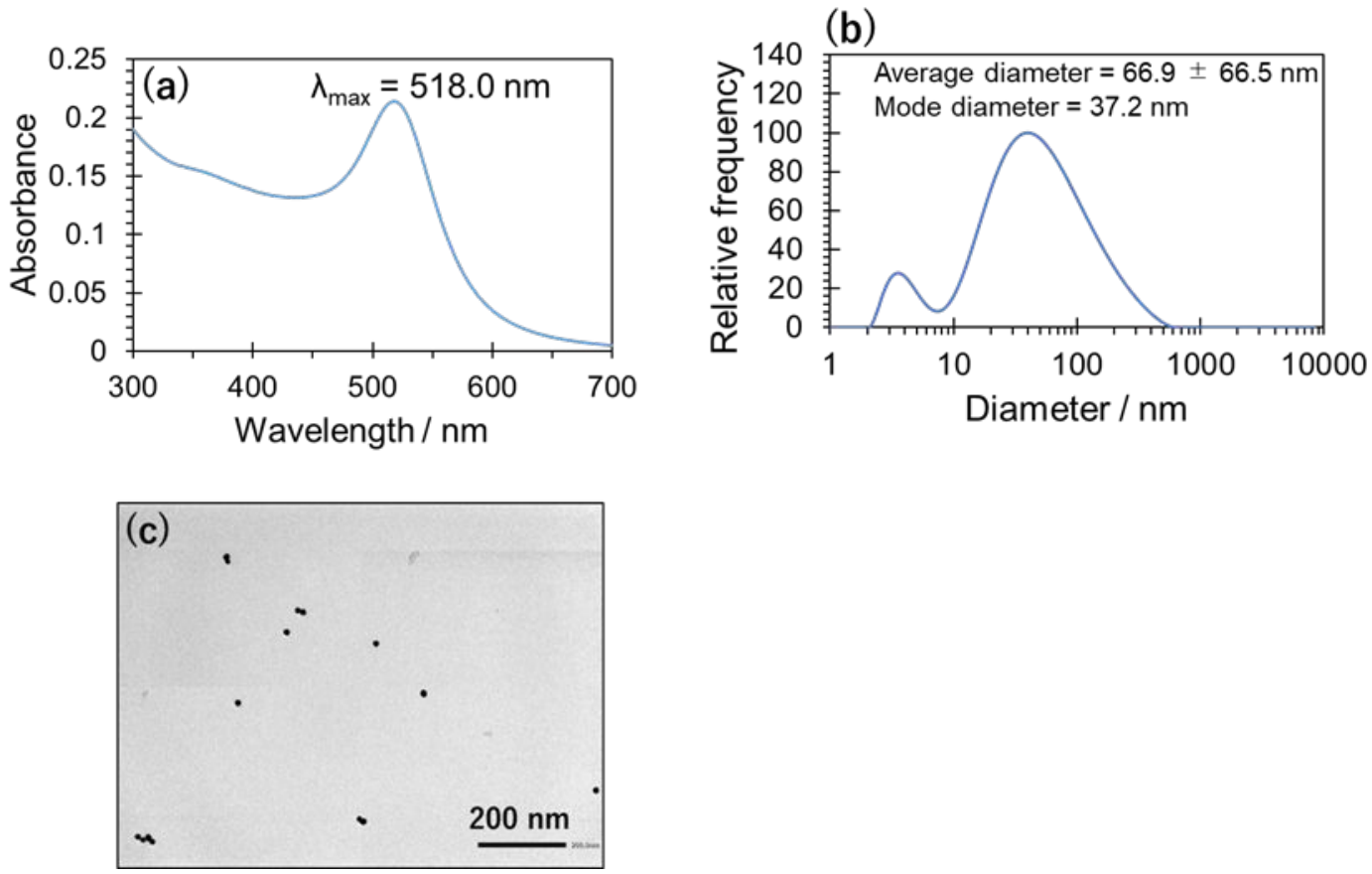

Figure S3 Characterization of Au-NPs prepared by trisodium citrate; (a) absorption spectrum of Au-NPs, (b) DLS profile, (c) TEM photograph. 


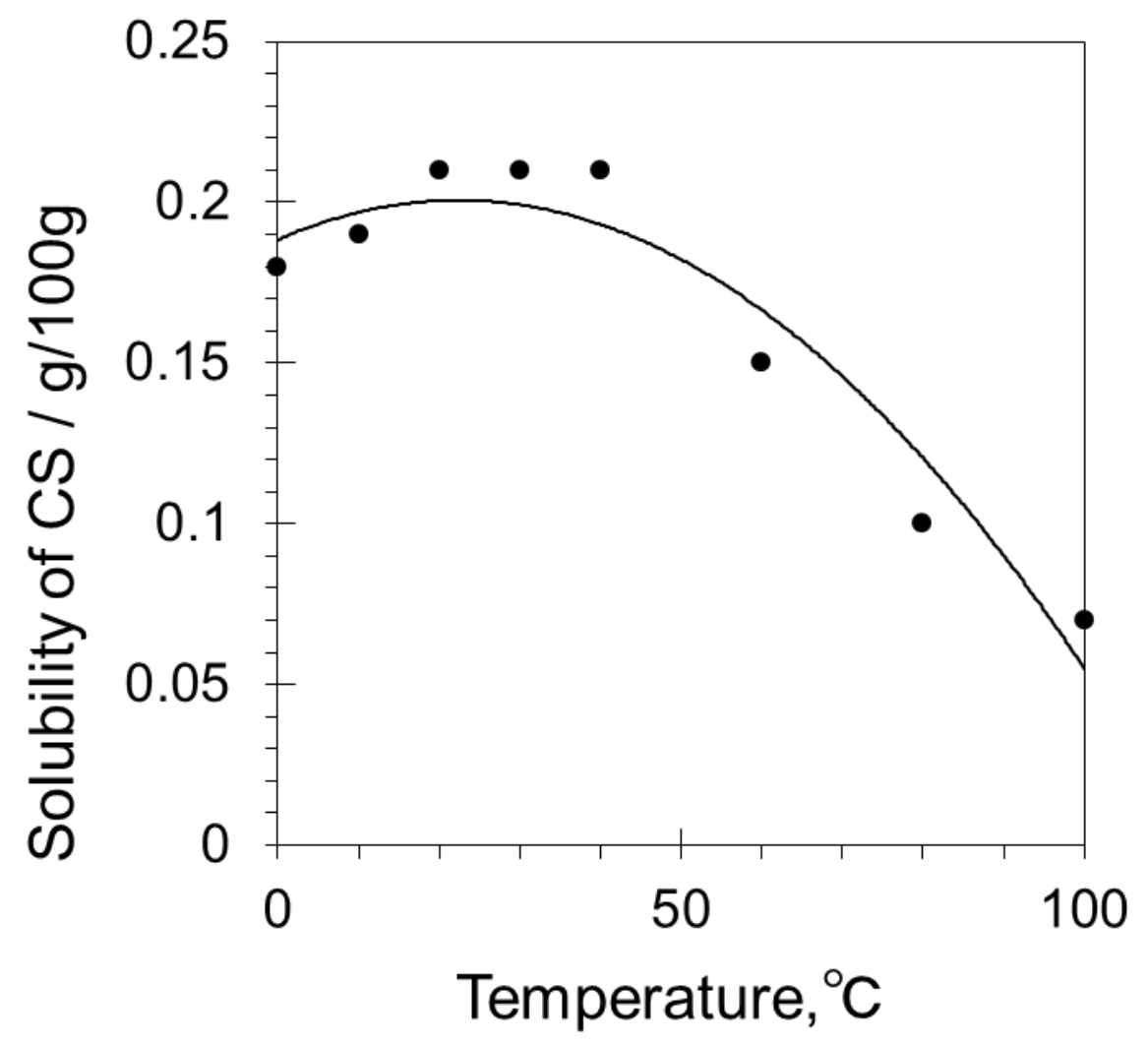

Figure S4. The solubility of CS at different temperatures ${ }^{4}$.

Note: Very similar plots have also been reported for the variation of the solubility of calcium sulfates with temperature in the literature. ${ }^{5}$ 


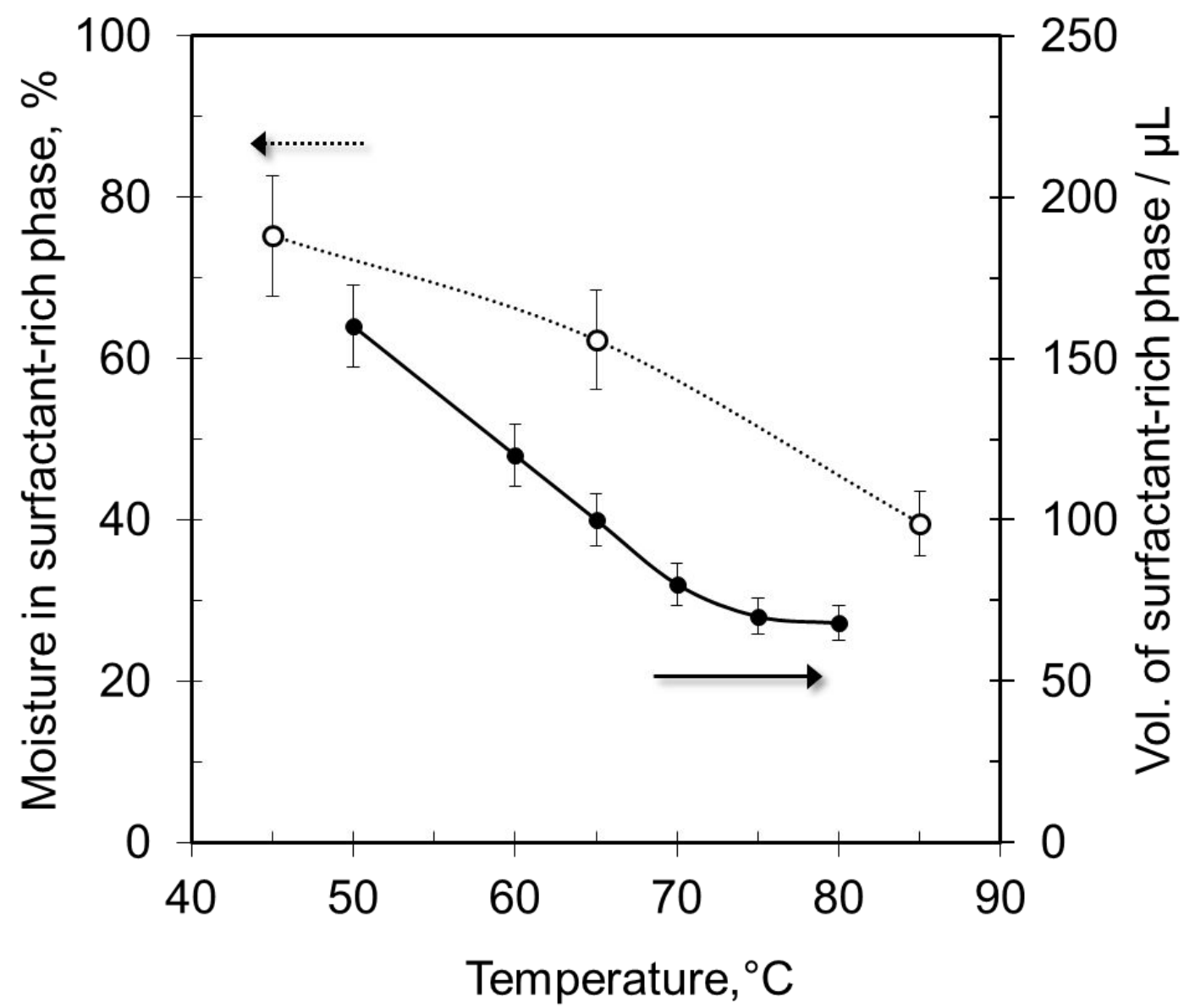

Figure S5. The impact of temperature on the volume of and percent water in the Triton X-114 surfactant-rich phase. 
References

(1) Mulfinger, L.; Solomon, S. D.; Bahadory, M.; Jeyarajasingam, A. V.; Rutkowsky, S. A.; Boritz, C. Synthesis and Study of Silver Nanoparticles. J. Chem. Educ. 2007, 84 (2), 322.

(2) Lee, P. C.; Meisel, D. Adsorption and Surface-Enhanced Raman of Dyes on Silver and Gold Sols. J. Phys. Chem. 1982, 86 (17), 3391-3395.

(3) Keating, C. D.; Musick, M. D.; Keefe, M. H.; Natan, M. J. Kinetics and Thermodynamics of Au Colloid Monolayer Self-Assembly: Undergraduate Experiments in Surface and Nanomaterials Chemistry. J. Chem. Educ. 1999, 76 (7), 949.

(4) The Chemical Society of Japan, ed.; The Chemical Society of Japan. Handbook of Chemistry: Pure Chemistry, 5th Ed., 5th ed.; Maruzen Pubulication: Tokyo, 2004.

(5) Luo, K.; Li, C.; Xiang, L.; Li, H.; Ning, P. Influence of Temperature and Solution Composition on the Formation of Calcium Sulfates. Particuology 2010, $8(3), 240-244$. 